\title{
Controle da adipogênese por ácidos graxos
}

\author{
Control of adipogenesis by fatty acids
}

Jean César Farias de Queiroz ${ }^{1 *}$, Maria Isabel Cardoso Alonso-Vale ${ }^{1 *}$, Rui Curi², Fabio Bessa Lima²

Trabalho realizado no Departamento de Fisiologia e Biofísica, Instituto de Ciências Biomédicas (ICB), Universidade de São Paulo (USP), São Paulo, SP, Brasil ' Laboratório de Fisiologia Celular, Departamento de Fisiologia e Biofísica, ICB USP, São Paulo, SP, Brasil ${ }^{2}$ Departamento de Fisiologia e Biofísica, ICB, USP, São Paulo, SP, Brasil

"Estes autores contribuíram igualmente para este artigo

Correspondência para: Fabio Bessa Lima

Departamento de Fisiologia e Biofísica, ICB, USP

Av. Professor Lineu Prestes, 1.524 05508-900 - São Paulo, SP, Brasil fabio@icb.usp.br

Recebido em 13/Mai/2009 Aceito em 9/Jun/2009

\section{RESUMO}

A obesidade é um dos principais problemas de saúde pública. Indivíduos obesos são mais suscetíveis a desenvolver doenças cardiovasculares e diabetes melito tipo 2. A obesidade resulta do aumento no tamanho e no número de adipócitos. $O$ balanço entre adipogênese e adiposidade determina o grau de obesidade do indivíduo. Adipócitos maduros secretam adipocinas, tais comoTNF $\alpha$, IL-6, leptina e adiponectina, e lipocina, o ácido palmitoleico $\omega$-7. A produção de adipocinas é maior na obesidade, o que contribui para o estabelecimento de resistência periférica à insulina. $O$ conhecimento dos eventos moleculares que regulam a diferenciação dos pré-adipócitos e de células-tronco mesenquimais em adipócitos (adipogênese) é importante para o entendimento da gênese da obesidade. A ativação do fator de transcrição PPAR $\gamma$ é essencial na adipogênese. Certos ácidos graxos são ligantes de PPAR $\gamma$ e podem, assim, controlar a adipogênese. Além disso, alguns ácidos graxos atuam como moléculas sinalizadoras em adipócitos, regulando sua diferenciação ou morte. Dessa forma, a composição lipídica da dieta e os agonistas de PPAR $\gamma$ podem regular o balanço entre adipogênese e morte de adipócitos e, portanto, a obesidade. Arq Bras Endocrinol Metab. 2009;53(5):582-94.

Descritores

Adipogênese; tecido adiposo; ácidos graxos; obesidade; PPAR gama; C/EBP- $\alpha$

\section{ABSTRACT}

Obesity is one of the major Public Health problems. Obese individuals are more susceptible to develop cardiovascular diseases and type 2 diabetes mellitus. The obesity results from the increase in size and number of the adipocytes. The balance between adipogenesis and adiposity determines the degree of obesity. Mature adipocytes secrete adipokines, such as TNF $\alpha$, IL-6, leptine and adiponectin, and lipokine, the palmitoleic acid $\omega$-7. The production of adipokines is increased in obesity, contributing to the onset of peripheral insulin resistance. The knowledge about the molecular events that regulate the differentiation of pre-adipocytes and mesenchymal stem cells into adipocytes (adipogenesis) is important for the comprehension of the genesis of obesity. Activation of transcription factor PPAR $\gamma$ plays an essential role in the adipogenesis. Certain fatty acids are PPAR $\gamma$ ligands and can control adipogenesis. Moreover, some fatty acids act as signaling molecules regulating their differentiation into adipocytes or death. Accordingly, the lipid composition of the diet and PPAR $\gamma$ agonists can regulate the balance between adipogenesis and death of adipocytes and, therefore, the obesity. Arq Bras Endocrinol Metab. 2009;53(5):582-94.

Keywords

Adipogenesis; adipose tissue; fatty acids; obesity; PPAR gamma; C/EBP- $\alpha$

\section{A OBESIDADE COMO PROBLEMA DE SAÚDE PÚBLICA}

A obesidade é uma doença crônica complexa, caracterizada por excesso de gordura corporal. É um dos principais problemas de saúde pública no mundo e afeta não apenas nações industrializadas, mas também países em desenvolvimento, tornando-se fator de risco para doenças cardíacas e diabetes (1). Apesar da atual consciência pública sobre as consequências da obesidade, sua incidência continua a aumentar. $\mathrm{O}$ mundo oci- 
dental tem experimentado um crescimento expressivo na prevalência da obesidade, em consequência do desequilíbrio energético decorrente do aumento na ingestão calórica somado à inatividade física e ao declínio concomitante do gasto energético.

Algumas alterações coexistem comumente em indivíduos obesos como, por exemplo, hiperglicemia, hiperlipidemia e hipertensão arterial sistêmica (2). A adiposidade leva ao desenvolvimento simultâneo dessas alterações funcionais que, coletivamente, compõem a chamada síndrome metabólica (SM). A obesidade está diretamente relacionada ao desenvolvimento de diabetes melito tipo 2 (DMT2), doença coronariana, acidente vascular cerebral, osteoartrite, apneia do sono e cânceres de mama, colo e ovário (3).

A produção de adipocinas pelo tecido adiposo desempenha função-chave nas complicações cardiometabólicas induzidas pela obesidade. Na obesidade, o tecido adiposo está infiltrado por macrófagos ativados, os quais também liberam quantidade excessiva de citocinas pró-inflamatórias, tais como o fator- $\alpha$ de necrose tumoral (TNF- $\alpha$ ), o inibidor 1 de ativador de plasminogênio (PAI-1), interleucina-6 (IL-6), proteína 4 ligadora de retinol, proteína 1 quimioatrativa de macrófagos (MCP-1) e proteínas de fase aguda (4). Esses fatores exercem ações parácrinas, que perpetuam a inflamação local no tecido adiposo, e endócrinas, que induzem à resistência à insulina e a disfunções vascular e cardíaca. Além disso, recentemente foi demonstrado que fatores secretados por macrófagos prejudicam a diferenciação de células adiposas em humanos (5).

Estudos epidemiológicos descreveram correlações entre o tipo de lipídeo consumido na dieta, a composição de ácidos graxos no tecido adiposo, a concentração destes no sangue e a incidência de certas doenças metabólicas (6). Dietas ricas em ácidos graxos saturados aumentam a resistência à insulina e a incidência de doenças cardiovasculares. Por sua vez, aquelas ricas em ácidos graxos mono- e poli-insaturados protegem o desenvolvimento dessas doenças (7).

Os ácidos eicosapentaenoico (EPA) $(\mathrm{C} 20: 5, \omega-3) \mathrm{e}$ docosa-hexaenoicoo (DHA) (C22:6, $\omega$-3), ambos poliinsaturados, são abundantes em peixes, ostra e mamíferos marinhos, e são escassos ou ausentes em animais terrestres e plantas. Os ácidos graxos $\omega$-3 são essenciais para o crescimento e desenvolvimento normal do organismo (8). O ácido DHA é um componente importante dos fosfolípides de membrana plasmática, especialmente em cérebro e retina (9). Adicionalmente, ácidos graxos $\omega-3$ possuem propriedades anti-inflamatória, antitrombótica, antiarrítmica e vasodilatadora, e alguns destes efeitos são modulados por prostaglandinas e leucotrienos (9). Efeitos benéficos dos ácidos graxos $\omega$-3 foram observados em relação ao colesterol e a triacilgliceróis e nas funções cardiovascular e imunológica (10).

Os ácidos graxos $\omega$-3 podem desempenhar função importante no tratamento adjuvante de doenças cardíacas, hipertensão, dislipidemia e DMT2 (10). Esses ácidos graxos são reguladores da expressão de genes envolvidos no metabolismo de lipídeos e de glicose e na adipogênese, atuando via PPARs (9). Além disso, a administração de óleo de peixe reduz o conteúdo de mRNA hepático da SREBP-1 (do inglês sterol regulatory element-binding protein-1), que também controla a expressão de genes lipogênicos (11).

\section{TECIDO ADIPOSO COMO LIBERADOR DE MOLÉCULAS BIOATIVAS: IMPLICAÇÕES NA OBESIDADE}

A visão tradicional do tecido adiposo como um depósito de lipídeos tem sido contestada desde a descoberta de algumas moléculas bioativas produzidas nele, como o fator endócrino adipsina (12). Em 1994, a identificação da leptina estabeleceu definitivamente esse tecido como um órgão endócrino. Desde então, mais de uma centena de peptídeos bioativos, a maioria deles capazes de atuar como verdadeiros hormônios, foi descrita como produto liberado pelo tecido adiposo (13). Essas proteínas compartilham propriedades estruturais com as citocinas, sendo a maioria delas produzida e secretada exclusivamente pelo tecido adiposo e denominada genericamente "adipocinas".

Entre as diversas adipocinas secretadas pelo tecido adiposo, destacam-se a leptina, a adiponectina, a adipsina, a resistina, o TNF- $\alpha$, o PAI- 1 , as interleucinas $1 \beta, 6$ e 8 (IL-1 $\beta, 6$ e 8 ), o fator 1 de crescimento insulina-símile (IGF-1), a MCP-1 e a visfatina, entre outros. Com exceção quase que única da adiponectina, a produção e a secreção desses diversos fatores se intensificam com a obesidade (14), sendo muitos deles, como o TNF- $\alpha$, a resistina, o PAI-1, a IL-6 e a MCP-1, diretamente associados à indução de resistência à insulina, à hipercoagulabilidade e à aterogênese, que, por sua vez, geram hipertensão, intensificação de estados pró-inflamatórios, aumento de riscos cardiovasculares e acidentes tromboembólicos (15). A concentração de IL-6 plasmática é considerada um marcador de DMT2 e doenças cardiovasculares (16). 
Por outro lado, a obesidade diminui os valores plasmáticos de adiponectina em roedores e humanos (17). A queda da adiponectina plasmática observada nos indivíduos obesos (hipoadiponectinemia) é um fator de risco independente para DMT2 e complicações cardiovasculares (18). Além da sua função como sensibilizadora da insulina, a adiponectina pode proteger a maioria das principais patologias relacionadas à obesidade, incluindo hipertensão, aterosclerose, esteatose hepática, falência cardíaca, inflamação das vias aéreas e câncer de mama (19). A leptina também desempenha função importante na manutenção da homeostase metabólica, incluindo a sensibilidade à insulina, na regulação dos depósitos energéticos, diminuindo a ingestão alimentar e aumentando o gasto energético (20), e na fertilidade. Além disso, foi recentemente identificada uma molécula lipídica, o ácido palmitoleico (C16:1, $\omega-7)$, descrito como uma lipocina sintetizada e secretada pelo tecido adiposo, com habilidade de também associar este tecido ao controle do metabolismo sistêmico. Esse ácido graxo atua como sinal hormonal que emerge do tecido adiposo e aumenta a sensibilidade do fígado e dos músculos à insulina (21).

\section{A OBESIDADE E A ADIPOGÊNESE}

Dois tipos de tecido adiposo com propriedades funcionais bem distintas são classicamente descritos em mamíferos: tecido adiposo branco (TAB) e tecido adiposo marrom (TAM). Ambos estão envolvidos no balanço energético, mas enquanto o TAM é especializado na dissipação de energia na forma de calor durante a termogênese induzida pelo frio e pela dieta, o TAB está principalmente envolvido na estocagem de energia na forma de triacilgliceróis.

O TAB é o principal reservatório energético do organismo, estocando lipídeos na forma de triacilgliceróis (TAG). Ele contém adipócitos, pré-adipócitos (células precursoras de adipócitos), células endoteliais, células do estroma vascular, fibroblastos, leucócitos e macrófagos. Adicionalmente, podem-se isolar neste tecido células-tronco mesenquimais, que podem ser direcionadas para diversas linhagens celulares, incluindo miócitos, condrócitos, osteoblastos e adipócitos (22). A elevação da massa adiposa ocorrida na obesidade é determinada pelo aumento do tamanho do adipócito (hipertrofia) e/ou do seu número (hiperplasia).

Modificações no tamanho (diâmetro e volume) de adipócitos maduros ocorrem em resposta à ativação de suas ações metabólicas típicas, que são a lipogênese e a lipólise. Tais alterações variam de acordo com a necessidade de incorporação ou liberação de lipídeos, que dependem, entre outros fatores, do estado nutricional do indivíduo, do seu gasto energético, da influência de hormônios (catabólicos ou anabólicos), da atividade de enzimas envolvidas nestes processos e da heterogeneidade característica existente entre os diversos grupamentos adiposos do organismo (23). Por outro lado, modificações no número de adipócitos (hiperplasia) dependem da diferenciação dos pré-adipócitos em adipócitos - processo denominado adipogênese. Assim, a compreensão detalhada do processo de diferenciação pode permitir melhor entendimento e/ou controle da adiposidade.

Como mencionado, o desenvolvimento da obesidade resulta não só da hipertrofia, mas da hiperplasia das células de gordura. O aumento do tamanho dos adipócitos não é um processo ilimitado. Eventualmente, seu crescimento atinge um grau máximo, além do qual a sua capacidade de armazenamento de gordura se exaure, $\mathrm{e}$ novas células são lentamente recrutadas e emergidas desse tecido. Adipócitos muito grandes, além do esgotamento da capacidade de estocagem de gordura, tornam-se mais lipolíticos. Isso pode desencadear aumento na concentração de ácidos graxos livres no plasma e danificar a função de órgãos não adiposos, num processo identificado lipotoxicidade (24). Adipócitos maduros são naturalmente protegidos dessa lipotoxicidade em razão de sua alta capacidade de detoxificação de ácidos graxos. Por outro lado, $15 \%$ a $50 \%$ das células que constituem o tecido adiposo correspondem a um reservatório de células-tronco mesenquimais, que incluem préadipócitos e são capazes de se dividir e se diferenciar em resposta a vários agentes extracelulares. Essas células, entretanto, possuem uma capacidade muito limitada de sintetizar e estocar lipídeos neutros (25).

A expansão do TAB durante a obesidade infantil também resulta da combinação de ambos - hipertrofia e hiperplasia dos adipócitos. Por muito tempo, acreditouse que adultos apresentariam número fixo de adipócitos e que mudanças na massa adiposa eram principalmente secundárias a alterações no volume de gordura da célula. Não obstante, adipócitos adultos exibem renovação notavelmente intensa e constante (26); atualmente, sabe-se que o potencial de gerar novas células persiste durante toda a vida do indivíduo.

Os adipócitos provêm de células-tronco mesenquimais multipotentes, residentes no estroma do tecido adiposo. Essas células multipotentes tornam-se pré-adipó- 
citos quando perdem a habilidade de se diferenciar em outras linhagens mesenquimais e tornam-se "comprometidas" com a linhagem adipocitária. Essa fase inicial da diferenciação do adipócito, ainda pouco caracterizada, é conhecida como determinação ou comprometimento. A segunda fase da adipogênese é a diferenciação terminal. Os pré-adipócitos adquirem as características de adipócitos maduros, acumulando gotas lipídicas e a habilidade de responder a hormônios como a insulina. A diferenciação terminal consiste na ativação de eventos transcricionais em cascata. $\mathrm{O}$ conhecimento sobre a adipogênese aumentou bastante nas últimas duas décadas, com o uso de células clonais e não clonais precursoras de adipócitos provenientes de roedores e humanos. Glicocorticoides, insulina e fator de crescimento semelhante à insulina (IGF-I) foram identificados como os mais eficientes agentes adipogênicos em experimentos ex vivo (27).

\section{REGULAÇÃO TRANSCRICIONAL DA ADIPOGÊNESE}

O processo de adipogênese tem sido bastante estudado por meio de modelos celulares ex vivo. O modelo mais bem caracterizado utiliza pré-adipócitos da linhagem celular 3T3-Ll (células oriundas de embriões de camundongos suíços extraídas prematuramente). O emprego de coquetéis estimulantes constituídos classicamente por insulina (Ins), dexametasona (Dex), metilisobutilxantina (MIX) e soro bovino fetal (FBS) desencadeiam o processo de adipogênese (28).

A diferenciação dessas células compreende estágios precisamente controlados: parada do ciclo celular, expansão clonal e diferenciação (eventos iniciais, intermediários e terminais), por meio da ativação de centenas de genes anteriormente silenciosos. A exposição de uma placa de pré-adipócitos 3T3-Ll confluentes ao coquetel adipogênico ativa receptores de glicocorticoides (pela dexametasona), receptor de IGF-1 (pela insulina) e a via de sinalização do AMPc (pelo MIX, um inibidor de fosfodiesterases), o que leva à ativação dos eventos iniciais representados pela expressão das proteínas ligantes ao amplificador CCAAT (CCAAT/enhancer binding proteins, $\mathrm{C} / \mathrm{EBPs}$ ): C/EBP- $\beta$ e C/EBP- $\delta$. As células, então, reiniciam o ciclo celular, sofrem divisão celular de forma regulada (expansão clonal), saem permanentemente do processo de ciclo celular e entram em diferenciação terminal por ativação do receptor gama ativado por proliferadores de peroxissomas - PPAR $\gamma$ e C/EBP- $\alpha$, os dois reguladores centrais do processo adipogênico (29) (Figura 1).

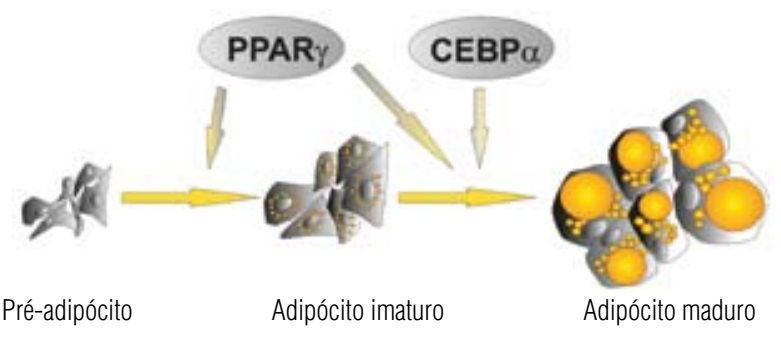

Figura 1. Modelo simplificado da adipogênese. Pré-adipócitos são induzidos para se diferenciar em adipócitos imaturos sob controle do PPAR $\gamma$ principalmente, o qual também induz a expressão de C/EBP $\alpha$. PPAR $\gamma$ e C/EBP $\alpha$ atuam coordenadamente para regular a conversão de adipócitos imaturos em adipócitos maduros.

$\mathrm{Na}$ confluência, os pré-adipócitos expressam os marcadores muito precoces de diferenciação, como LPL (lipase de lipoproteínas) e colágeno tipo VI, a qual é induzida pelo contato célula-célula. Após uma hora da adição do coquetel, ocorre a expressão transiente de proto-oncogenes $c$-fos, $c-j u n$ e $m y c$, que dão início à mitose pós-confluente, importante para que ocorra o desenovelamento das hélices de DNA, permitindo o acesso de fatores de transcrição a elementos responsivos presentes em genes-alvos envolvidos na modulação do fenótipo do adipócito maduro, cuja expressão cessa entre duas e três horas depois do tratamento.

$\mathrm{C} / \mathrm{EBP}-\beta$ e $-\delta$ são os primeiros fatores de transcrição induzidos após a exposição das células ao coquetel de diferenciação - de forma que é postulado o fato de estarem diretamente envolvidos no processo de diferenciação, em resposta a indutores hormonais. A expressão do C/EBP- $\delta$ cessa após 48 horas, enquanto que o declínio do C/EBP- $\beta$ é mais gradual - por volta do oitavo dia pós-diferenciação. C/EBP- $\beta$ e C/EBP- $\delta$ ativam a expressão de PPAR $\gamma$, que é transcricionalmente induzida durante o segundo dia pós-indução da diferenciação, sendo máxima por volta do terceiro ou quarto dia. C/EBP- $\beta$ e C/EBP- $\delta$ também induzem a expressão de $\mathrm{C} / \mathrm{EBP}-\alpha$, que chega a expressão máxima entre o quarto e o quinto dia da diferenciação. Uma vez ativados os reguladores centrais da adipogênese, $\mathrm{C} / \mathrm{EBP}-\alpha$ e PPAR $\delta$, estes se autorregulam positivamente para se manter expressos, ou seja, retroalimentam a indução da sua própria expressão, apesar da redução da expressão de C/EBP- $\beta$ e - $\delta$ (Figura 2 ). C/EBP- $\alpha$ e PPAR $\delta$ induzem transcrição de mais de uma centena de genes-alvos anteriormente silenciosos, incluindo enzimas e proteínas envolvidas na geração e na manutenção do fenótipo do adipócito, como aquelas envolvidas no transporte de glicose sensível à insulina, lipogênese, lipólise e síntese e secreção de adipocinas. Os dois fatores são críticos e decisivos para os estágios tardios de diferenciação de 
maneira cooperativa e sinérgica, mas não são expressos em altos níveis nos pré-adipócitos e não estão envolvidos no desenvolvimento inicial.

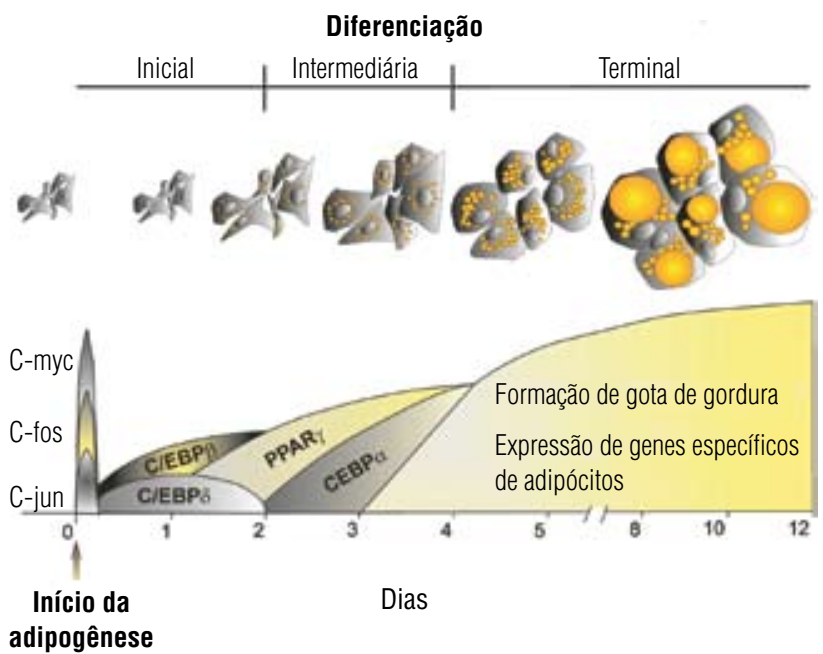

Figura 2. Progressão da diferenciação de adipócitos. Alguns eventos da diferenciação dos adipócitos estão representados cronologicamente. As áreas demarcadas com os respectivos fatores de transcrição representam o período da expressão gênica durante a diferenciação. Os vários estágios da diferenciação (inicial, intermediária e terminal) também estão evidenciados. Na diferenciação terminal, quando ocorre a formação da gota de gordura, os genes PPAR $\gamma$ e CEPB $\alpha$ também são expressos. Uma vez ativados, esses dois fatores centrais da adipogênese regulam um ao outro positivamente, para manter sua expressão gênica, apesar da redução da expressão de C/EBP $\beta$ e $\delta$. C/EBP $\alpha$ e PPAR $\gamma$ induzem a transcrição de muitos genes do adipócito, incluindo enzimas e proteínas envolvidas na geração e na manutenção do fenótipo dessa célula. Entretanto, embora ambos os fatores sejam importantes nos estágios tardios de diferenciação, eles não estão envolvidos no desenvolvimento inicial, pois não são expressos nesta fase. Figura adaptada de: Ntambi \& Young-Cheul, 2000.

Em adição aos C/EBPs e PPAR $\gamma$ (fatores integrados a uma rede transcricional controladora da adipogênese), outros fatores também regulam esse processo (29).

Em roedores e humanos, ácidos graxos de cadeia longa atuam no estágio inicial e induzem a formação dos adipócitos. A primeira evidência de que os ácidos graxos estão envolvidos na adipogênese foi obtida após purificação do principal componente adipogênico do soro bovino fetal, o ácido araquidônico (ARA, C20:4 $\omega-5)$. In vitro, o ARA é um fator adipogênico que atua no pré-adipócito como precursor de prostaciclina (30). Por sua vez, os ácidos eicosapentaenoico (EPA, C20:5 $\omega$-3) e DHA (C22:6 $\omega$-3), que não são metabolizados à prostaciclina, são menos potentes do que o ARA. O efeito adipogênico do ARA é parcialmente bloqueado por anticorpos inibidores de ciclo-oxigenase e antiprostaciclina adicionados ao meio de cultura, sendo este efeito reproduzido por carbaciclina, um análogo estável da prostaciclina (31). Esses achados são sugestivos do papel adipogênico da prostaciclina $\left(\mathrm{PGI}_{2}\right)$ por meio do seu receptor, atuando por mecanismo autócrino/parácrino. Entre os ácidos graxos naturais (saturados, monoinsaturados e poli-insaturados, apenas o ARA leva à produção de AMPc e ativa a via da cinase proteica $\mathrm{A}$, pelo sistema I receptor de prostaglandina/prostaciclina.

Com base no fato de que ácidos graxos são ligantes de PPAR $\gamma$, uma descrição mais detalhada desse fator de transcrição será útil para melhor entendimento da ação dos ácidos graxos sobre a adipogênese.

\section{PPARS: 0 PPAR $\gamma$ NA ADIPOGÊNESE}

Os receptores ativados por PPARs pertencem a um subgrupo da superfamília de receptores nucleares, do qual três diferentes tipos foram descritos até o momento: $\operatorname{PPAR} \alpha, \operatorname{PPAR} \delta$ e PPAR $\gamma$. Embora compartilhem propriedades estruturais comuns, apresentam funções e distribuição diferentes entre os tecidos. O acoplamento de um ligante ao domínio específico do receptor promove a sua dimerização com o receptor do ácido cis-retinoico $\mathrm{X}$ (RXR) e sua ligação a sequências específicas do DNA localizadas na região promotora de genes-alvos conhecidas como elementos responsivos ao PPAR (PPREs) (Figura 3). Os vários PPARs respondem aos diferentes ligantes com diferentes afinidades pelos PPREs e também interagem com os mais diversos cofatores, incluindo coativadores e correpressores (32).

O PPAR $\alpha$ foi o primeiro a ser clonado. Foi descrito em 1990 como um receptor nuclear que se liga a muitos compostos naturais e sintéticos e que induz a proliferação de peroxissomas em roedores (33). É expresso principalmente no fígado, no músculo esquelético, no coração, no rim e em baixos níveis no tecido adiposo. Admite-se que essa distribuição tecidual tenha importância na $\beta$-oxidação de ácidos graxos (33). Em estudos recentes, foi mostrado que a ativação do PPAR $\alpha$ por agonistas específicos pode ser promissora para o tratamento da aterosclerose (34).

PPAR $\delta$ também é expresso em muitos tecidos (32). Estudos utilizando camundongos knockout revelam que esse fator transcricional está envolvido em várias atividades metabólicas, incluindo aumento da termogênese, transporte e oxidação de ácidos graxos no músculo esquelético, coração e tecido adiposo e diminuição da captação de glicose no fígado (35).

O PPAR $\gamma$ foi primeiramente identificado em Xenopus e depois em camundongo (36). Graves e cols. (37) isolaram o PPAR $\gamma$ por identificação e clonagem do fator (então denominado ARF6) que controlava a função de 


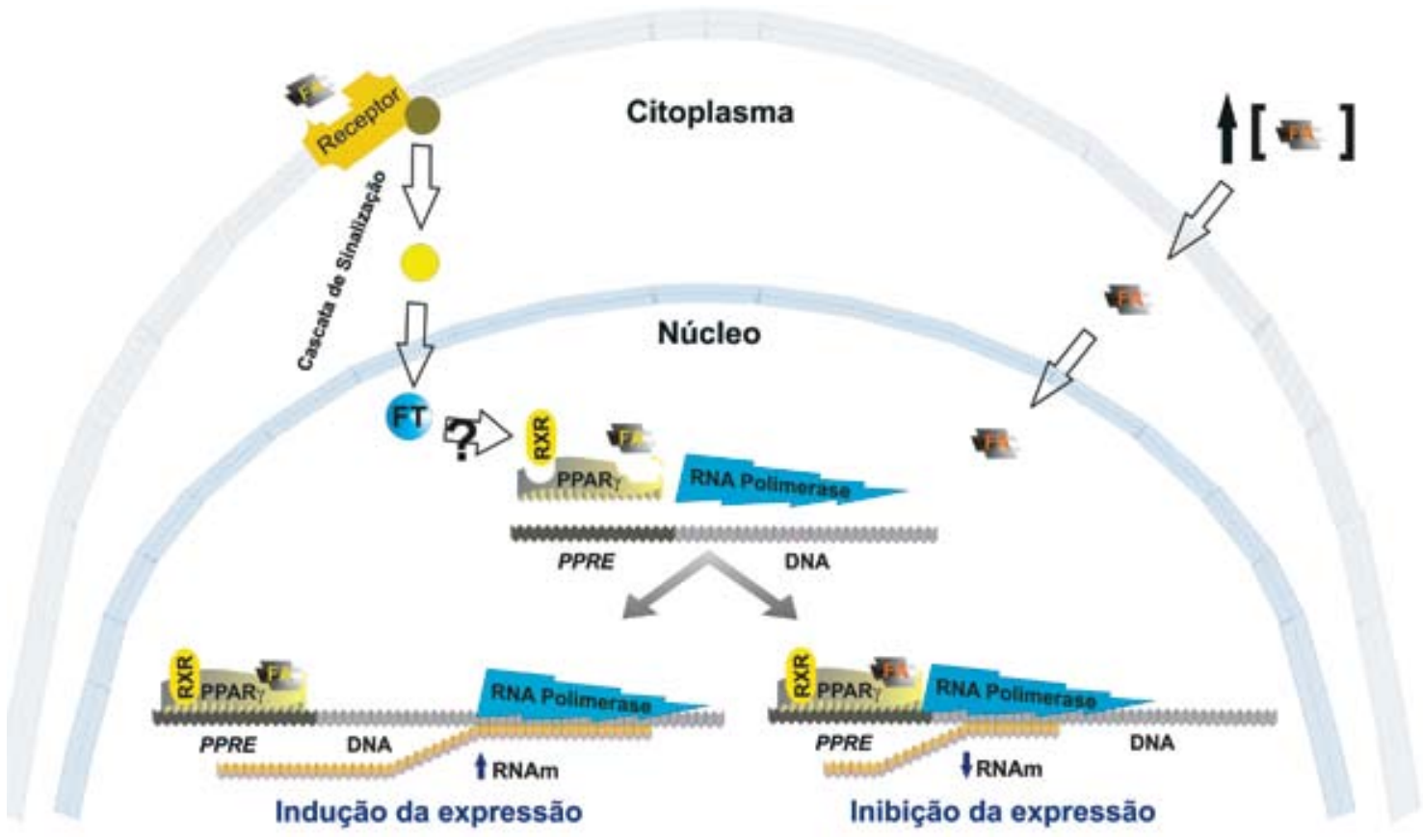

FT: fator de transcrição; FA: ácidos graxos (do inglês fatty acids).

Figura 3. Controle da ligação do PPAR y ao PPRE por seus ligantes. Os ácidos graxos podem penetrar livremente a célula, ou se ligarem a receptores, tais como G-proteincoupled receptors (GPCRs) e toll-like receptor 4 (TLR4), que ativam cascatas de sinalização. A ligação do PPARy ao PPRE (sequência de nucleotídeos na região promotora denominada elementos responsivos ao PPAR) depende da ligação do RXR e de mais um ligante, que pode ser um ácido graxo. Alguns ácidos graxos, quando ligados ao PPAR $\gamma$, auxiliam sua ligação ao PPRE, enquanto outros bloqueiam essa ligação, inibindo a expressão dos genes relacionados à adipogênese.

um promotor lipo-específico do gene aP2. Com o reconhecimento de que o sítio de ligação no DNA para esse fator era um elemento responsivo a hormônio, eles, então, usaram PCR (reação em cadeia da polimerase) para clonar o fator de ligação, que foi reconhecido como sendo o PPAR $\gamma(38)$.

A identificação e a caracterização do PPAR $\gamma$ foram fundamentais para o entendimento da fisiologia do tecido adiposo. Duas isoformas foram identificadas, PPAR $\gamma 1$ e $\gamma 2$, geradas por splicing alternativo do mesmo gene. PPAR $\gamma 2$ é idêntico ao PPAR $\gamma 1$, exceto pelo fato deste último conter 30 aminoácidos adicionais na região N-terminal. Ao contrário do PPAR $\gamma 1$, o qual é amplamente expresso nos diferentes tecidos, a expressão do PPAR 2 é restrita ao tecido adiposo (38).

O PPAR $\gamma$ regula muitos processos biológicos, incluindo o metabolismo lipídico, a homeostase da glicose, inflamação e aterogênese e a adipogênese (39). O PPAR $\gamma$ tem sido descrito como o regulador central da adipogênese. A expressão ectópica de PPAR $\gamma 2$ em fibroblastos em cultura direciona a diferenciação das células em adipócitos (38). Estudos de perda de função em células fibroblásticas também demonstram que o PPAR $\gamma$ é essencial para a diferenciação de adipócitos (40).
A identidade dos ligantes biológicos para PPAR $\gamma$ permanece não resolvida e esta é uma área de investigação intensa. Evidências circunstanciais sugerem que um ativador endógeno de PPAR $\gamma$ é produzido durante a adipogênese (41). Vários estudos mostraram que ácidos graxos poli-insaturados e moléculas relacionadas ativam o PPAR $\gamma$ (42). O intrigante é que o PPAR $\gamma$ responde fracamente a ácidos graxos quando comparado a PPAR $\alpha$ e PPAR $\delta$, alimentando especulações sobre ácidos graxos modificados tanto como ligantes biológicos. Certos prostanoides, incluindo a 15-desoxi$\Delta \mathrm{l} 2,14$ prostaglandina $\mathrm{J} 2$ (15- $\Delta \mathrm{PGJ} 2)$, o primeiro ligante natural descrito, são excelentes ativadores de $\operatorname{PPAR} \gamma(32,41)$. Entretanto, é improvável que o 15$\triangle$ PGJ2 esteja presente em concentrações suficientes in vivo para ser um ligante biológico significante. Ácidos graxos oxidados, como o 9-HODE encontrado em LDL (do inglês low-density lipoprotein) oxidada, ativa o PPAR $\gamma$ com potência aumentada e eficácia relativa, quando comparado a ácidos graxos nativos e está presente em concentrações não desprezíveis em lesões ateroscleróticas (43). Entretanto, ainda não está claro se ácidos graxos oxidados servem como ativadores em outros tecidos. 
É possível que diferentes ligantes para PPAR $\gamma$ possam ter importância primária em outros contextos. Por exemplo, o ligante que ativa o PPAR $\gamma$ na adipogênese pode ser distinto dos que o ativam em macrófagos na parede da artéria. Outros lipídeos, como os ácidos graxos nitrados e o ácido lisofosfatídico, também têm sido identificados como ativadores de PPAR $\gamma$ (44). A importância dessas moléculas na função do PPAR $\gamma$ deve ser estabelecida. Por outro lado, grande número de ligantes sintéticos tem sido descoberto. As tiazolinedionas (TZDs), incluindo pioglitazona, roziglitazona e troglitazona, constituem um grupo importante de ativadores sintéticos de PPAR $\gamma$ grandemente empregados como sensibilizadores da insulina no tratamento do diabetes. A estrutura dos TZDs determina a especificidade de ativação de PPAR $\gamma$ em genes alvos específicos (45).

$A$ ativação do PPAR $\gamma$ na adipogênese envolve uma cascata transcricional que inclui membros da família do C/EBP. Com base em estudos em cultura de células, um modelo coerente, no qual o tratamento hormonal de pré-adipócitos induz $\mathrm{C} / \mathrm{EBP}-\beta$ e $-\delta$, foi desenvolvido. A partir daí, essas proteínas ligam-se diretamente ao PPAR $\gamma$, ativando-o.

PPAR $\gamma$, sob ação do ligante, induz muitos genes- alvos envolvidos na lipogênese e adipogênese, e isto também ativa a expressão do C/EBP- $\alpha$. Este se liga ao sítio do C/EBP no promotor do PPAR $\gamma$. A evidência genética para esse cenário é clara: PPAR é suficiente e necessário para a diferenciação da célula adiposa, como já descrito acima. A sua expressão em células que não expressam C/ EBP- $\alpha$ promove diferenciação normal do adipócito. Por outro lado, C/EBP- $\alpha$ não possui a habilidade de promover a adipogênese na ausência do $\operatorname{PPAR} \gamma(46)$.

\section{OS ÁCIDOS GRAXOS E A ADIPOGÊNESE}

A primeira linha de evidências de que os ácidos graxos (fatty acids, FA) estão envolvidos na adipogênese foi a identificação do ácido ARA como o principal componente adipogênico no soro bovino fetal (55).

Evidências adicionais de que os FA são importantes reguladores da adipogênese foram obtidas quando se observou que os FA de cadeia longa (LCFA) podem atuar como reguladores transcricionais de alguns genes relacionados ao metabolismo de lipídeos (47), como é o caso do gene da proteína ligadora de lipídeos do adipócito (ALBP), também chamada de proteína ligadora de ácido graxo do adipócito (a-FABP) ou proteína aP2 (48). Ao contrário do ARA, que é metabolizado à prostaciclina em pré-adipócitos clonais, os LCFAs precisam ser metabolizados para apresentarem efeitos. O $\alpha$-bromo-palmitato, um LCFA que não é metabolizado, é mais potente ativador da expressão desses genes do que LCFAs naturais (49).

Uma breve exposição de pré-adipócitos aos LCFA é suficiente para disparar hiperplasia e hipertrofia in vitro, de modo similar à situação observada in vivo sob dieta rica em palmitato por dez dias (48). Essas observações sobre o papel adipogênico dos LCFAs como reguladores transcricionais também foram descritas para ratos e pré-adipócitos humanos não clonais (27).

Sob estímulo do coquetel adipogênico, demonstrouse que os FA ativam a diferenciação de pré-adipócitos (50). No entanto, quando essas células são expostas ao oleato, acumulam TAG ao mesmo tempo ou antecedendo a indução de genes adipogênicos, enquanto células tratadas com o coquetel expressam os genes adipogênicos antes do acúmulo de TAG (51).

Dieta rica em triglicerídeos de cadeia média (TCM) diminui a hiperplasia e a hipertrofia de adipócitos em roedores (52). Esse efeito de TCMs parece diminuir a massa de gordura por inibição da adipogênese (53). Estudos em 3T3-Ll mostraram que o octanoato, um ácido graxo de cadeia media, diminui a adipogênese interferindo nas expressões gênica e proteica de PPAR $\gamma$, C/EBP- $\alpha$, e SREBPlc (53). Em ensaios clínicos, humanos alimentados com dieta contendo TCMs obtiveram redução da massa corporal $(54,55)$. Entretanto, a redução da gordura corporal foi atribuída aos efeitos dos TCMs sobre a oxidação de ácidos graxos.

Como ativadores/ligantes de PPAR $\beta / \delta$ e $\operatorname{PPAR} \gamma$, ácidos graxos não esterificados (NEFAs) atuam no estágio de pré-adipócito e não necessitam ser metabolizados a acil-CoA para aumentar a formação de TAG em adipócitos (48). Deve ser salientado que pré-adipócitos não contêm TAG, mas possuem a capacidade de sintetizar lipídeos complexos para a biossíntese de membrana (48). Além disso, pré-adipócitos podem retomar a proliferação em resposta a ácidos graxos, metabolizados ou não pela ativação do $\operatorname{PAAR} \beta / \delta(56)$.

Filhotes de camundongos alimentados com uma dieta rica em ácido linoleico (LA, C18:2 $\omega$-6) tornaram-se $40 \%$ mais pesados no desmame e com massa gorda aumentada quando comparados aos que receberam uma alimentação balanceada de ácido linoleico e ácido linonênico combinados (LNA, C18:3 $\omega$-3) - uma diferença corporal que foi mantida na vida adulta (57). A inclusão de LNA em uma dieta isocalórica rica em LA 
previne o aumento da massa gorda, em concordância com estudos in vitro e in vivo de que PUFA $\omega$-3 reduz a lipogênese e aumenta a $\beta$-oxidação de ácidos graxos (58). Em conjunto, essas observações sugerem que PUFA $\omega-6$ e $\omega-3$ afetam diferencialmente o balanço entre a proliferação de células precursoras de adipócitos e sua diferenciação.

Os ácidos EPA (C20:5, $\omega$-3) e DHA (C22:6, $\omega$-3) são abundantes em peixe, ostra e mamíferos marinhos e escassos ou ausentes em animais terrestres e plantas. Os ácidos graxos $\omega$-3 são essenciais para o crescimento normal e para o desenvolvimento (8).

Em ratos que receberam sacarose durante 15 semanas, observam-se adiposidade visceral e aumento moderado no peso corporal. Soria e cols. (59) mostraram que a administração de óleo de peixe aos animais reverte parcialmente as alterações metabólicas e morfológicas do tecido adiposo epidermal. $\mathrm{O}$ óleo de peixe reduz a massa de gordura, a hipertrofia dos adipócitos e melhora a distribuição corporal de gordura via ativação do PPAR $\gamma$.

Pighin e cols. (60) mostraram que a adiposidade e a resistência à insulina, observadas pela administração de sacarose durante 270 dias em ratos, ocorrem concomitantemente com a diminuição dos valores plasmáticos de leptina e adiponectina sem alteração na expressão de genes da gordura visceral. A substituição do óleo de milho por óleo de peixe eleva os valores plasmáticos de ambas adipocinas, reduz a resistência à insulina e reverte a dislipidemia e a adiposidade. Embora os mecanismos pelos quais o óleo de peixe aumenta os valores de leptina e adiponectina no plasma ainda não estejam esclarecidos, a elevação de ambas as adipocinas desempenha papel essencial na normalização da resistência à insulina e adiposidade.

EPA e, em menor extensão, DHA inibem o efeito estimulatório do ARA na produção de cAMP (61). A produção de prostaciclina cessa no adipócito em que o receptor de prostaciclina na superfície celular não é funcional (61). Acredita-se que a produção de prostaciclina e seu efeito no aumento do conteúdo de cAMP representam eventos transientes da adipogênese.

Dieta rica em ácidos graxos poli-insaturados pode modular a expressão de proteínas no tecido adiposo por vários mecanismos. Eles podem causar redução ou aumento da transcrição de genes e modular modificações pós-traducionais de proteínas (62). Os ácidos graxos poli-insaturados (PUFAs) suprimem a transcrição de genes lipogênicos, pela inibição da expressão da proteína ligante do elemento regulatório do esterol (SRE$\mathrm{BPs})$, e podem atuar como antagonistas do receptor $\mathrm{X}$ do ácido retinoico (LXR) (63) e como ligante/ativador dos PPARs (Figura 3). Os ácidos graxos atuam também como ativadores/inibidores de sequências de reações, tais como a via da serina cinase que otimiza a via de sinalização da insulina e o transporte de glicose (64).

Ácidos linoleicos conjugados (CLA) formam um grupo de isômeros posicionais e geométricos do ácido linoleico $(\mathrm{Cl}$ 8:2 $\omega-6)$. Os dois isômeros predominantes do CLA, que foram primeiramente identificados na carne de ruminantes, produtos do leite e derivados, são cis-9 trans-11 e trans-10 cis-12 (65). Originalmente descritos como compostos com potencial anticarcinogênico, os isômeros de CLA têm também sido estudados na prevenção ou na atenuação da obesidade (66). Mistura de isômeros de CLA, especificamente trans-10 cis-12, previne o desenvolvimento da obesidade in vivo e o acúmulo de triglicerídeos em adipócitos in vitro (67).

A ação do CLA pode ser proveniente do efeito do isômero CLA trans-10 cis-12 que diminui a expressão de genes específicos de adipócitos, assim como o número de células precursoras e o acúmulo de lípides em cultura de tecido adiposo subcutâneo de porcos neonatos. No entanto, o CLA cis- 9 trans-11 não alterou a adipogênese nessas condições experimentais (68).

O tratamento com CLA cis- 9 trans- 11 e trans- 10 cis12 foi testado sobre a biologia de pré-adipócitos e adipócitos humanos SGBS (do inglês Simpson-Golabi-Behmel syndrome). Ambos inibiram igualmente a proliferação de pré-adipócitos de maneira dose-dependente e o acúmulo de lipídeos durante a diferenciação. $\mathrm{O}$ tratamento com altas doses de CLA induziu apoptose em pré-adipócitos, células em diferenciação e adipócitos, com efeito mais pronunciado do isômero trans-10 cis-12 (69).

Além do CLA potencializar a apoptose induzida por ajoene - um dissulfureto insaturado, extraído do alho (Allium sativum) - em adipócitos 3T3-Ll maduros, por meio de aumento sinérgico da expressão de vários genes pró-apoptóticos (70), foi demonstrado, também nesta condição, que o tratamento com CLA PEGilado ( $\mathrm{PEG}$ CLA) causa desdiferenciação dessas células pela redução da expressão do $\operatorname{PPAR} \gamma_{2}(71)$.

\section{OS ÁCIDOS GRAXOS COMO MOLÉCULAS SINALIZADORAS}

Ácidos graxos liberados da membrana celular pela ação de fosfolipases ou disponíveis no meio extracelular são moléculas de sinalização, as quais podem atuar como segundos mensageiros. Suas concentrações são altera- 
das rapidamente em resposta à ligação de agonistas específicos a receptores de membrana plasmática (72).

Os eicosanoides são mediadores lipídicos produzidos a partir do processamento de certos ácidos graxos pelas enzimas ciclo-oxigenases (COX) e lipo-oxigenases (LOX) e do citocromo P450. Na adipogênese, o ARA induz adipogênese indiretamente por meio da produção de prostaciclina, ocasionando a produção do cAMP (31). Por outro lado, a indução da adipogênese por ácidos graxos pode ser direta como sinalizador em receptores. $\mathrm{O}$ ácido palmítico induz a adipogênese em pré-adipócitos clonais e estimula a produção da $\mathrm{aP} 2$, um receptor para ácidos graxos. $\mathrm{O} \alpha$-bromopalmitato, uma molécula de palmitato ligada ao bromo e não metabolizável nas células, causou estimulação similar à da adipogênese, $\mathrm{e}$ a produção da aP2 foi ainda maior, demonstrando que ácidos graxos podem atuar não só como fonte energética para adipócitos, mas também como moléculas sinalizadoras para o início da adipogênese (48).

O processo de apoptose é controlado por uma ampla gama de moléculas de sinalização celular, com origem extracelular (indutores extrínsecos) ou intracelular (indutores intrínsecos). Foi demonstrado, em algumas situações, que os ácidos graxos podem atuar como indutores de apoptose em adipócitos, interferindo, assim, na celularidade do TAB. O DHA, numa concentração de $100 \mu \mathrm{M}$, causou apoptose em adipócitos 3T3-L1, mas não foi tóxico para seus respectivos pré-adipócitos (73), demonstrando um efeito protetor da adipogênese. Da mesma forma, o CLA causou apoptose em linhagens adipocitárias de camundongos $(71,74)$ e em adipócitos humanos (75).

Recentemente, o ácido palmitoleico (Cl6:1 $\omega$-7) foi proposto como uma lipocina - molécula produzida pelo adipócito que atua como sinalizadora em diversos órgãos, o que regula a homeostase metabólica sistêmica, estimulando a ação da insulina no músculo e suprimindo a esteatose hepática (21). Se essa importante molécula lipídica produzida e secretada pelo tecido adiposo desempenha também um papel autócrino e/ou parácrino, bem como efeitos sobre a adipogênese, é um fato que permanece por ser investigado.

\section{ADIPOGÊNESE NO ORGANISMO VIVO}

Até meados do século passado, o tecido adiposo era considerado uma estrutura terminal, do ponto de vista da sua diferenciação - isto é, uma vez concluída a diferenciação, o tecido não mais se renovaria. Contudo, são acumuladas evidências de que essa concepção não está correta. Primeiramente, são inúmeras as demonstrações de que é possível extrair desse tecido células similares a fibroblastos com alta potencialidade de diferenciação. Células fibroblasto-símiles oriundas do tecido adiposo (76), após estimulação adequada, diferenciam-se em condrócitos e osteoblastos, além, obviamente, de adipócitos, o que abriu campo de pesquisas com perspectivas imensas. Em segundo lugar, foi descrita recuperação de massa adiposa após lipectomia ou desnervação do TAB (77). Os autores atribuem a recuperação pós-lipectomia da massa adiposa ao efeito induzido pela desnervação pós-cirúrgica, de modo que o aporte de informação sensorial a respeito do tamanho da massa adiposa para o sistema nervoso central estaria comprometido, resultando em resposta compensatória neural. Isso só ocorre porque, na região lipectomizada ou lipodesnervada, pré-adipócitos remanescentes se multiplicam e se diferenciam recompondo o tecido.

Em estudo recente, Spalding e cols. (26) avaliaram o desenvolvimento do tecido adiposo mediante a determinação do conteúdo de ${ }^{14} \mathrm{C}$ resultante da contaminação radioativa da atmosfera a partir do pós-guerra, em consequência das duas explosões nucleares. Parte desse radioisótopo se acumulou no tecido adiposo e, pela determinação da radiatividade remanescente no tecido e uma análise matemática complexa, os autores chegaram à conclusão de que o número de adipócitos presentes no TAB se mantém constante ao longo da vida do indivíduo, independentemente de ganho ou perda de peso. Por outro lado, no mesmo estudo, os autores calcularam uma possível taxa de renovação do tecido em seres humanos e concluíram que o tecido adiposo se renova completamente a cada oito ou nove anos. Esses autores mencionam que a renovação do tecido se deve a um balanço entre a geração de novos adipócitos para substituir células mais antigas que entram em processo de apoptose. Pesquisas feitas em ratos, avaliando o ritmo de desaparecimento de timina ${ }^{-14} \mathrm{C}$ previamente incorporada ao TAB, determinaram que a sobrevida média de uma célula adiposa nesta espécie animal é da ordem de 140 dias (78).

Há pouca informação sobre o fenômeno da adipogênese in vivo. Embora seja possível induzir-se adipogênese em células fibroblasto-símiles extraídas do TAB de animais ou mesmo de humanos, não há metodologia padronizada ou estabelecida para se determinar e quantificar o fenômeno in vivo. Essa dificuldade tem 
levado pesquisadores a questionarem se a adipogênese realmente ocorre nos organismos vivos.

Contrariamente à dificuldade de se estudar adipogênese in vivo e considerando-se que a renovação do tecido adiposo implica substituição de adipócitos mortos por novas células, o processo da morte celular (apoptose) é muito bem estudado e demonstrado (79).

As resistências em se admitir a ocorrência de adipogênese vêm sendo paulatinamente vencidas e o desafio maior é o de se entender a importância desse processo para a fisiologia do tecido adiposo e suas relações com demais processos importantes como o controle geral do metabolismo, do comportamento alimentar e do peso corporal. O entendimento da fisiologia do tecido adiposo e das relações entre as taxas de adipogênese e de apoptose do tecido é fundamental para que seja estabelecida a gênese da obesidade e da SM. A compreensão da dinâmica entre adipogênese e apoptose do tecido adiposo permitirá interferir, por meio de tratamento medicamentoso e da dieta, no desenvolvimento da obesidade e moléstias metabólicas (DMT2, SM, aterosclerose) reduzindo o potencial risco de lesão cardíaca, vascular e neural.

\section{PERSPECTIVAS E RISCOS DA APLICAÇÃO TERAPÊUTICA DA ADIPOGÊNESE}

$\mathrm{O}$ excesso de FA livres circulantes é forte indutor de resistência periférica à ação da insulina, aumentando a probabilidade de desenvolvimento de DMT2 e de SM. Considerando que o TAB armazena e fornece ácidos graxos conforme as necessidades energéticas do organismo, sua participação no controle do fluxo desses metabólitos é extremamente importante para o organismo. O tecido adiposo protege os outros órgãos e tecidos do acúmulo ectópico de gordura e da consequente lipotoxicidade que esse fenômeno provoca. A lipotoxicidade, por sua vez, é uma causa importante de resistência à insulina. É importante enfatizar que $\mathrm{o}$ adipócito apresenta características metabólicas que o tornam menos suscetível à lipotoxicidade. A geração de novas células adiposas pode atuar como mecanismo de atenuação desse quadro, pois aumenta a celularidade sem acúmulo exacerbado de gordura.

Em indivíduos obesos, o tecido adiposo se apresenta hipertrofiado. Paralelamente, a obesidade cursa com alto grau de atividade inflamatória, especialmente no próprio tecido adiposo. Muitas das citocinas pró-inflamatórias geradas nesse tecido, pela infiltração de ma- crófagos ou pela produção dessas pelo próprio adipócito, causam resistência à insulina nesse tecido, limitando sua função.

$\mathrm{O}$ equilíbrio entre a atividade hiperplásica e hipertrófica do tecido adiposo determina o número de células nesse tecido. Na obesidade, o predomínio de células hipertrofiadas reduz o fluxo sanguíneo, o que leva, em última instância, à hipóxia neste tecido, à inflamação e à infiltração de macrófagos (80). Os macrófagos liberam fatores que prejudicam o processo adipogênico em células humanas (5) (Figura 4). Ocorre ainda diminuição da capacidade tamponante de lipídeos (pelo tecido adiposo) com consequente deposição ectópica de gordura nos demais tecidos. Esse fato, somado à produção anormal de adipocinas, é responsável pelos distúrbios associados à obesidade, como, por exemplo, a resistência à insulina.

Adipócitos hipertrofiados são produtores importantes de citocinas pró-inflamatórias (TNF $\alpha$, IL6, ILl $\beta$, resistina, MCPl) ao mesmo tempo que apresentam limitação na capacidade de sintetizar e liberar uma importante adipocina anti-inflamatória, a adiponectina esta adipocina é o mais potente sensibilizador endógeno da insulina. A estimulação da adipogênese in vivo pode substituir células adiposas hipertrofiadas por
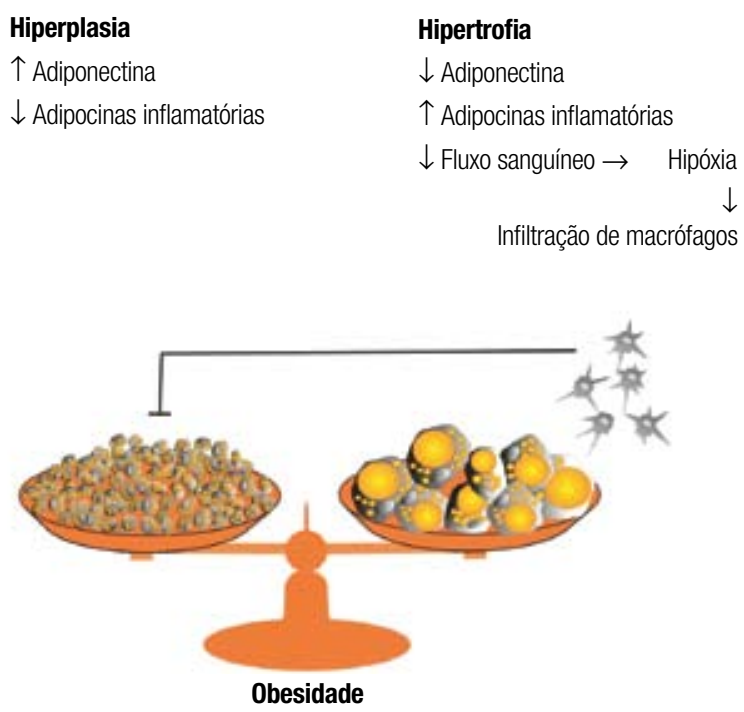

Figura 4. Balanço entre hiperplasia e hipertrofia do tecido adiposo. A obesidade é determinada pelo aumento do tamanho do adipócito e do seu número. A adipogênese pode levar à formação de um grande número de novos adipócitos (hiperplasia), que produzem mais adiponectina e menor quantidade de adipocinas inflamatórias. Por outro lado, adipócitos volumosos (hipertrofia) produzem menos adiponectina e mais adipocinas inflamatórias. 0 "alagamento" dos adipócitos no tecido adiposo ocasiona uma redução do fluxo sanguíneo com consequente hipóxia e infiltração de macrófagos. As citocinas produzidas pelos macrófagos (tais como o TNF $\alpha$, o PAl-1, IL-6, proteína 4 ligadora de retinol, MCP-1 e proteínas de fase aguda) inibem a adipogênese. 
adipócitos jovens, menores e com maior capacidade de produzir adiponectina em detrimento das adipocinas pró-inflamatórias.

Até que ponto seria benéfico propiciar que a hiperplasia (ou adipogênese) se sobrepusesse à hipertrofia das células? Células jovens produzem mais adiponectina, mas a hiperplasia também é um evento que leva à obesidade. Por outro lado, esse recrutamento celular é lento e diminui com a idade, mas o organismo tende a manter constante o número de células, ou seja, à medida que células novas vão sendo recrutadas, células "envelhecidas" hipertrofiadas são substituídas. De qualquer forma, essas células recém-diferenciadas amadurecem, hipertrofiam-se e passam a assumir característica oposta. Com a hipertrofia dos adipócitos, adviria a obesidade, e os efeitos benéficos da adipogênese são perdidos. Não se trata de descartar a ideia de ativar a adipogênese com objetivos terapêuticos, mas apenas de se ponderar sobre a sua importância. Há situações em que sua estimulação pode ser extremamente benéfica. É o caso de síndromes lipodistróficas. Outras situações, como o envelhecimento, se desenvolvem com uma forte atenuação da capacidade adipogênica dos pacientes. Aí, também, a terapia pró-adipogênica poderia ser benéfica para a saúde.

Em moléstias nas quais a resistência à insulina é reconhecidamente um fator agravante - quando não causal - como o DMT2 e a SM, estratégias terapêuticas foram desenvolvidas para atuar na resistência à insulina. Uma família de fármacos com a característica de antirresistência à insulina, as tiazolidinedionas (TZDs), ganhou notoriedade por sua eficácia terapêutica, e sua utilização tem sido intensa. As TZDs têm, como mecanismo básico de ação, a propriedade de se ligar ao $\operatorname{PPAR} \gamma$, o fator central da adipogênese, ativando-o. Esse receptor nuclear é também potente estimulador da expressão gênica da adiponectina. Se, por um lado, o efeito de antirresistência à insulina é marcante, por outro, efeitos colaterais indesejáveis costumam ocorrer com seu emprego, por um período de tempo mais prolongado.

Além das TZDs, o PPAR $\gamma$ pode ser ativado por compostos de natureza lipídica, alguns dos quais, como vimos, podem ser seus ligantes naturais. Certos ácidos graxos poli-insaturados, como o ARA, são precursores da 15-desoxi-PGJ ${ }_{2}$, podendo participar de forma indireta como ativadores de PPAR $\gamma$. O próprio ARA e o LA se ligam ao PPAR $\gamma$, embora a afinidade seja reduzida (81).
O emprego de dietas ricas em lipídeos com potencial pró-adipogênico, como ácidos graxos poli-insaturados $\omega-6$, ARA e LA, ou monoinsaturados, como ácido palmitoleico $\omega-7$, podem constituir uma estratégia terapêutica coadjuvante ao uso de TZDs, por se tratar de ligantes de PPAR $\gamma$. Dessa forma, um efeito sinérgico poderia ser obtido na ativação da adipogênese e da sensibilização à insulina, com a importante vantagem terapêutica de reduzir a dose de TZDs (e, portanto, seus efeitos colaterais), possibilitando seu uso por tempo mais prolongado. Essas constatações devem ser consideradas na formulação de dietas que empregam lipídeos e que, consequentemente, favorecem o processo adipogênico, o que poderia amenizar o quadro de resistência à insulina e distúrbios associados.

Declaração: os autores declaram não haver conflitos de interesse científico neste estudo.

\section{REFERÊNCIAS}

1. Oglesby AK, Secnik K, Barron J, Al-Zakwani I, Lage MJ. The association between diabetes related medical costs and glycemic control: a retrospective analysis. Cost Eff Resour Alloc. 2006;4:1.

2. Kaplan NM. The deadly quartet. Upper-body obesity, glucose intolerance, hypertriglyceridemia, and hypertension. Arch Intern Med. 1989;149(7):1514-20.

3. Kahn BB, Flier JS. Obesity and insulin resistance. J Clin Invest. 2000;106(4):473-81.

4. Tilg $H$, Moschen AR. Adipocytokines: mediators linking adipose tissue, inflammation and immunity. Nat Rev Immunol. 2006;6(10):772-83.

5. Permana PA, Menge C, Reaven PD. Macrophage-secreted factors induce adipocyte inflammation and insulin resistance. Biochem Biophys Res Commun. 2006;341(2):507-14.

6. Warensjö E, Sundström J, Lind L, Vessby B. Factor analysis of fatty acids in serum lipids as a measure of dietary fat quality in relation to the metabolic syndrome in men. Am J Clin Nutr. 2006;84(2):442-8.

7. Wohlers M, Nascimento CM, Xavier RA, Ribeiro EB, Silveira VL. Participation of corticosteroids and effects of indomethacin on the acute inflammatory response of rats fed $n-6$ or $n-3$ polyunsaturated fatty acid-rich diets. Inflammation. 2003;27(1):1-7.

8. Lombardo YB, Chicco AG. Effects of dietary polyunsaturated n-3 fatty acids on dyslipidemia and insulin resistance in rodents and humans. A review. J Nutr Biochem. 2006;17(1):1-13.

9. Jump DB. Dietary polyunsaturated fatty acids and regulation of gene transcription. Curr Opin Lipidol. 2002;13(2):155-64.

10. Simopoulos AP. Essential fatty acids in health and chronic disease. Am J Clin Nutr. 1999;70(3):560-9.

11. Clarke SD. Polyunsaturated fatty acid regulation of gene transcription: a molecular mechanism to improve the metabolic syndrome. J Nutr. 2001;131(4):1129-32.

12. Flier JS, Cook KS, Usher P, Spiegelman BM. Severely impaired adipsin expression in genetic and acquired obesity. Science. 1987;237(4813):405-8.

13. Lafontan M. Fat cells: afferent and efferent messages define new approaches to treat obesity. Annu Rev Pharmacol Toxicol. 2005;45:119-46. 
14. Frühbeck G, Gómez-Ambrosi J, Muruzábal FJ, Burrell MA. The adipocyte: a model for integration of endocrine and metabolic signaling in energy metabolism regulation. Am J Physiol Endocrinol Metab. 2001;280(6):E827-47.

15. Hauner $\mathrm{H}$. The new concept of adipose tissue function. Physiol Behav. 2004;83(4):653-8.

16. Fernández-Real JM, RicartW. Insulin resistance and chronic cardiovascular inflammatory syndrome. Endocr Rev. 2003;24(3):278-301.

17. Weyer $C$, Funahashi T, Tanaka S, Hotta K, MatsuzawaY, Pratley RE, et al. Hypoadiponectinemia in obesity and type 2 diabetes: close association with insulin resistance and hyperinsulinemia. J Clin Endocrinol Metab. 2001;86(5):1930-5.

18. Pischon T, Girman CJ, Hotamisligil GS, Rifai N, Hu FB, Rimm EB. Plasma adiponectin levels and risk of myocardial infarction in men. JAMA. 2004;291(14):1730-7.

19. Zhu W, Cheng KK, Vanhoutte PM, Lam KS, Xu A. Vascular effects of adiponectin: molecular mechanisms and potential therapeutic intervention. Clin Sci (Lond). 2008;114(5):361-74.

20. Jéquier E. Leptin signaling, adiposity, and energy balance. Ann N Y Acad Sci. 2002;967:379-88.

21. Cao H, Gerhold K, Mayers JR, Wiest MM, Watkins SM, Hotamisligil GS. Identification of a lipokine, a lipid hormone linking adipose tissue to systemic metabolism. Cell. 2008;134(6):933-44.

22. Konieczny SF, Emerson CP Jr. 5-Azacytidine induction of stable mesodermal stem cell lineages from 10T1/2 cells: evidence for regulatory genes controlling determination. Cell. 1984;38(3):791-800.

23. Jensen MD. Health consequences of fat distribution. Horm Res. 1997;48 Suppl 5:88-92.

24. DeFronzo RA. Dysfunctional fat cells, lipotoxicity and type 2 diabetes. Int J Clin Pract Suppl. 2004;(143):9-21.

25. Coleman RA, Lee DP. Enzymes of triacylglycerol synthesis and their regulation. Prog Lipid Res. 2004;43(2):134-76.

26. Spalding KL, Arner E, Westermark PO, Bernard S, Buchholz BA, Bergmann $\mathrm{O}$, et al. Dynamics of fat cell turnover in humans. Nature. 2008;453(7196):783-7.

27. 27. Ailhaud $G$, Hauner $H$. Development of white adipose tissue. In: Bray AGB, editor. Handbook of obesity: etiology and pathophysiology. New York, USA: Marcel Dekker; 2004.

28. Ntambi JM, Young-Cheul K. Adipocyte differentiation and gene expression. J Nutr. 2000;130(12):3122-6.

29. Farmer SR. Transcriptional control of adipocyte formation. Cell Metab. 2006;4(4):263-73.

30. Gaillard D, Négrel R, Lagarde M, Ailhaud G. Requirement and role of arachidonic acid in the differentiation of pre-adipose cells. Biochem J. 1989;257(2):389-97.

31. Darimont C, Vassaux G, Ailhaud G, Negrel R. Differentiation of preadipose cells: paracrine role of prostacyclin upon stimulation of adipose cells by angiotensin-II. Endocrinology. 1994;135(5):2030-6.

32. Kliewer SA, Lenhard JM, WillsonTM, Patel I, Morris DC, Lehmann JM. A prostaglandin J2 metabolite binds peroxisome proliferator-activated receptor gamma and promotes adipocyte differentiation. Cell. 1995;83(5):813-9.

33. Issemann I, Green S. Activation of a member of the steroid hormone receptor superfamily by peroxisome proliferators. Nature. 1990;347(6294):645-50.

34. Brown JD, Plutzky J. Peroxisome proliferator-activated receptors as transcriptional nodal points and therapeutic targets. Circulation. 2007;115(4):518-33.

35. Barish GD, Narkar VA, Evans RM. PPAR delta: a dagger in the heart of the metabolic syndrome. J Clin Invest. 2006;116(3):590-7.

36. Zhu Y, Alvares K, Huang Q, Rao MS, Reddy JK. Cloning of a new member of the peroxisome proliferator-activated receptor gene family from mouse liver. J Biol Chem. 1993:268(36):26817-20.
37. Graves RA, Tontonoz P, Platt KA, Ross SR, Spiegelman BM. Identification of a fat cell enhancer: analysis of requirements for adipose tissue-specific gene expression. J Cell Biochem. 1992; 49(3):219-24.

38. Tontonoz P, Hu E, Graves RA, Budavari Al, Spiegelman BM. mPPAR gamma 2: tissue-specific regulator of an adipocyte enhancer. Genes Dev. 1994;8(10):1224-34.

39. Koutnikova H, Cock TA, Watanabe M, Houten SM, Champy MF, Dierich $\mathrm{A}$, et al. Compensation by the muscle limits the metabolic consequences of lipodystrophy in PPAR gamma hypomorphic mice. Proc Natl Acad Sci U S A. 2003;100(24):14457-62.

40. Wu Z, Rosen ED, Brun R, Hauser S, Adelmant G, Troy AE, et al. Cross-regulation of C/EBP alpha and PPAR gamma controls the transcriptional pathway of adipogenesis and insulin sensitivity. Mol Cell. 1999;3(2):151-8.

41. Tzameli I, Fang H, Ollero M, Shi H, Hamm JK, Kievit P, et al. Regulated production of a peroxisome proliferator-activated receptorgamma ligand during an early phase of adipocyte differentiation in 3T3-L1 adipocytes. J Biol Chem. 2004;279(34):36093-102.

42. Kliewer SA, Sundseth SS, Jones SA, Brown PJ, Wisely GB, Koble $C S$, et al. Fatty acids and eicosanoids regulate gene expression through direct interactions with peroxisome proliferatoractivated receptors alpha and gamma. Proc Natl Acad Sci U S A. 1997;94(9):4318-23.

43. Nagy L, Tontonoz P, Alvarez JG, Chen H, Evans RM. Oxidized LDL regulates macrophage gene expression through ligand activation of PPARgamma. Cell. 1998;93(2):229-40.

44. Schopfer FJ, Lin Y, Baker PR, Cui T, Garcia-Barrio M, Zhang J, et al. Nitrolinoleic acid: an endogenous peroxisome proliferatoractivated receptor gamma ligand. Proc Natl Acad Sci U S A. 2005;102(7):2340-5.

45. Lehmann JM, Moore LB, Smith-Oliver TA, Wilkison WO, Willson TM, Kliewer SA. An antidiabetic thiazolidinedione is a high affinity ligand for peroxisome proliferator-activated receptor gamma (PPAR gamma). J Biol Chem. 1995;270(22):12953-6.

46. Rosen ED, Hsu CH, Wang X, Sakai S, Freeman MW, Gonzalez FJ, et al. C/EBPalpha induces adipogenesis through PPARgamma: a unified pathway. Genes Dev. 2002;16(1):22-6.

47. Amri EZ, Bertrand B, Ailhaud G, Grimaldi P. Regulation of adipose cell differentiation. I. Fatty acids are inducers of the aP2 gene expression. J Lipid Res 1991;32(9):1449-56.

48. Amri EZ, Ailhaud G, Grimaldi PA. Fatty acids as signal transducing molecules: involvement in the differentiation of preadipose to adipose cells. J Lipid Res. 1994;35(5):930-7.

49. Grimaldi PA, Knobel SM, Whitesell RR Abumrad NA. Induction of aP2 gene expression by nonmetabolized long-chain fatty acids. Proc Natl Acad Sci USA. 1992;89(22):10930-4.

50. Azain MJ. Role of fatty acids in adipocyte growth and development. J Anim Sci. 2004;82(3):916-24.

51. Xie W, Hamilton JA, Kirkland JL, Corkey BE, Guo W. Oleate-induced formation of fat cells with impaired insulin sensitivity. Lipids. 2006;41(3):267-71.

52. Geliebter A, Bracco EF, Van Itallie TB, Hashim SA. Medium-chain triglyceride diet and obesity. Int J Obes. 1984;8(2):191-2.

53. Han J, Hamilton JA, Kirkland JL, Corkey BE, Guo W. Mediumchain oil reduces fat mass and down-regulates expression of adipogenic genes in rats. Obes Res. 2003;11(6):734-44.

54. St-Onge M-P, Ross R, Parsons WD, Jones PJH. Medium-chain triglycerides increase energy expenditure and decrease adiposity in overweight men. Obes Res. 2003;11(3):395-402.

55. Tsuji H, Kasai M, Takeuchi H, Nakamura M, Okazaki M, Kondo K. Dietary medium-chain triacylglycerols suppress accumulation of body fat in a double-blind, controlled trial in healthy men and women. J Nutr. 2001;131(11):2853-9. 
56. Jehl-Pietri C, Bastie C, Gillot I, Luquet S, Grimaldi PA. Peroxisome-proliferator-activated receptor $\mathrm{d}$ mediates the effects of long-chain fatty acids on post-confluent cell proliferation. Biochem J. 2000; 350 Pt:93-8.

57. Massiéra F, Saint-Marc P, Seydoux J, Murata T, Kobayashi T, Narumiya $S$, et al. Arachidonic acid and prostacyclin signaling promote adipose tissue development: a human health concern? J Lipid Res. 2003;44(2):271-9.

58. Ukropec J, Reseland JE, Gasperikova D, Demcakova E, Madsen L, Berge RK, et al. The hypotriglyceridemic effect of dietary n-3 FA is associated with increased b-oxidation and reduced leptin expression. Lipids. 2003; 38(10):1023-9.

59. Soria A, Chicco A, Eugenia D'Alessandro M, Rossi A, Lombardo YB. Dietary fish oil reverse epididymal tissue adiposity, cell hypertrophy and insulin resistance in dyslipemic sucrose fed rat model small star, filled. J Nutr Biochem. 2002;13(4):209-18.

60. Pighin D, Karabatas L, Rossi A, Chicco A, Basabe JC, Lombardo YB. Fish oil affects pancreatic fat storage, pyruvate dehydrogenase complex activity and insulin secretion in rats fed a sucroserich diet. J Nutr. 2003;133(12):4095-101.

61. Vassaux G, Gaillard D, Darimont C, Ailhaud G, Negrel R. Differential response of preadipocytes and adipocytes to prostacyclin and prostaglandin E2: physiological implications. Endocrinology. 1992;131(5):2393-8.

62. Clarke SD. The multi-dimensional regulation of gene expression by fatty acids: olyunsaturated fats as nutrient sensors. Curr Opin Lipidol. 2004;15(1):13-8.

63. Yoshikawa T, Shimano $\mathrm{H}$, Yahagi $\mathrm{N}$, Ide T, Amemiya-Kudo M, MatsuzakaT, et al. Polyunsaturated fatty acids suppress sterol regulatory element-binding protein 1c promoter activity by inhibition of liver $X$ receptor (LXR) binding to LXR response elements. J Biol Chem. 2002;277(3):1705-11.

64. Delarue J, Magnan C. Free fatty acids and insulin resistance. Curr Opin Clin Nutr Metab Care. 2007;10(2):142-8.

65. Belury M. Inhibition of carcinogenesis by conjugated linoleic acid: potential mechanisms of action. J Nutr. 2002;132(0):2995-8.

66. Evans M, Brown JM, Mclntosh M. Isomer-specific effects of conjugated linoleic acid (CLA) on adiposity and lipid metabolism. J Nutr Biochem. 2002;13(9):508.

67. ParkY, Albright K, Storkson J, Liu W, Cook ME, Pariza M. Changes in body composition in mice during feeding and withdrawal of conjugated linoleic acid. Lipids. 1999;34(3):243-8.

68. Zhou X, Li D, Yin J, Ni J, Dong B, Zhang J, et al. CLA differently regulates adipogenesis in stromal vascular cells from porcine subcutaneous adipose and skeletal muscle. J Lipid Res. 2007;48(8):1701-9.
69. Fischer-Posovszky P, Kukulus V, Zulet MA, Debatin KM, Wabitsch M. Conjugated linoleic acids promote human fat cell apoptosis. Horm Metab Res. 2007;39(3):186-91.

70. Rayalam S, Della-Fera MA, Baile CA. Phytochemicals and regulation of the adipocyte life cycle. J Nutr Biochem. 2008;19(11):717-26.

71. Evans M, Geigerman C, Cook J, Curtis L, Kuebler B, McIntosh M. Conjugated linoleic acid suppresses triglyceride accumulation and induces apoptosis in 3T3-L1 preadipocytes. Lipids. 2000;35(8):899-910.

72. Bhattacharjee AK, Chang L, Chen M, White L, Bell JM, Bazinet RP, et al. Chronic $d$-amphetamine depresses an imaging marker of arachidonic acid metabolism in rat brain. Int $\mathrm{J}$ Neuropsychopharmacol. 2008;11(7):957-69.

73. Kim HK, Della-Fera M, Lin J, Baile CA. Docosahexaenoic acid inhibits adipocyte differentiation and induces apoptosis in 3T3L1 preadipocytes. J Nutr. 2006;136(12):2965-9.

74. Moon HS, Lee HG, Seo JH, Chung CS, KimTG, Kim IY, et al. Downregulation of PPARgamma2-induced adipogenesis by PEGylated conjugated linoleic acid as the pro-drug: Attenuation of lipid accumulation and reduction of apoptosis. Arch Biochem Biophys. 2006;456(1):19-29.

75. Seo JH, Moon HS, Kim IY, Guo DD, Lee HG, ChoiYJ, et al. PEGylated conjugated linoleic acid stimulation of apoptosis via a p53mediated signaling pathway in MCF-7 breast cancer cells. Eur J Pharm Biopharm. 2008;70(2):621-6.

76. Dicker A, Le Blanc K, Aström G, van Harmelen V, Götherström $C$, Blomqvist $L$, et al. Functional studies of mesenchymal stem cells derived from adult human adipose tissue. Exp Cell Res. 2005;308(2):283-90

77. Shi $\mathrm{H}$, BartnessTJ. White adipose tissue sensory nerve denervation mimics lipectomy-induced compensatory increases in adiposity. Am J Physiol Regul Integr Comp Physiol. 2005;289(2):R514-R520.

78. Klyde BJ, Hirsch J. Isotopic labeling of DNA in rat adipose tissue: evidence for proliferating cells associated with mature adipocytes. J. Lipid Res. 1979;20(6):691-704.

79. Murano I, Barbatelli G, Parisani V, Latini C, Muzzonigro G, Castellucci $\mathrm{M}$, et al. Dead adipocytes, detected as crown-like structures (CLS), are prevalent in visceral fat depots of genetically obese mice. J Lipid Res. 2008;49(7):1562-8

80. Goossens GH. The role of adipose tissue dysfunction in the pathogenesis of obesity-related insulin resistance. Physiol Behav. 2008;94(2):206-18.

81. lijima K, Yoshizumi M, Ako J, Eto M, Kim S, Hashimoto M, et al. Expression of peroxisome proliferator-activated receptor gamma (PPARgamma) in rat aortic smooth muscle cells. Biochem Biophys Res Commun. 1998;247(2):353-6. 